Emir. J. Agric. Sci. 2001. (13) : 11-17

http://www.cfs.uaeu.ac.ae/research/ejas.html

\title{
Myocardial dystrophy in camel calves in the United Arab Emirates (field cases)
}

\author{
A. A. El-Khouly, T. A. Abbas and T. Moustafa
}

Vet. Laboratory; Animal Resources; Agriculture Department and Licvestock, P.O. Box 1004, Al Ain, UAE

\begin{abstract}
Different young ages of calve-camels died from heart muscle dystrophy. This syndrome was attributed to selenium deficiency. The mortality rate recorded was as high as $10 \%$ in one camp. Hydro-thorax, severe lung edema, hydro-pericardium and various degrees of cardiac muscle necrosis were the most common pathological findings. The serum enzymes including creatine phosphokinase (CPK), Lactic dehydrogenase (LDH) and aspartate aminotransferase (AST) and Lactic acid were markedly increased. The selenium level in diseased cases was less than $35 \mathrm{ppb}$ in serum, less than $0.20 \mathrm{ppb}$ in liver and less than $0.65 \mathrm{ppb}$ in kidney tissues.
\end{abstract}

Keywords: white muscle disease, vitamin E, selenium, calves, camels

\section{Introduction}

Nutritional muscular dystrophy is a common problem in a variety of young animal species (Hutchinson et al., 1982). This is governed by the vitamin-E status of the animals or selenium (Se) deficiency (Horton, 1977). The Se deficiency is a widespread problem in the dromedaries (Zhang et al.,1986 and Hamliri, 1989). Recently a remarkable high incidence of calf-camel deaths due to heart muscle dystrophy was recorded at Al-Ain region, UAE. Among 45 dead calves-camels submitted to the Veterinary laboratory for necropsy due to different reasons a number of 12 cases showed signs of cardiac muscle dystrophy. This raises a question about the selenium levels in the diseased cases and the possibility of early diagnosis via studying the activity of serum enzymes. The post-mortum and histo-pathological findings of affected cases were described.

\section{Materials and Methods.}

\section{Animals}

Dead calves-camels were submitted to the veterinary laboratory. Department of Agriculture and Animal Resources in Al-Ain for necropsy. Among 45 dead cases sent to the laboratory for necropsy; a 12 cases showed signs of muscular dystrophy on post-mortum examination. The age of the studied cases varies from 2 to 12 weeks. Eight of these dead cases came from a single flock consisted of 80 calvescamels. The other calves came from different localities in Al-Ain region, UAE.

\section{Clinical pathology}

There is a chance to study the changes in blood picture and serum chemistry before death in eight cases .An EDTA blood samples were collected and examined using electronic hematology analyzer (Coulter counter electronic). Biochemical assays were performed on serum using clinical chemistry auto analyzer system (Dimension, DADE)

\section{Necropsy and Histopathology study}

At necropsy, the post-mortum findings were recorded. Tissue specimens were fixed in $10 \%$ formol saline. The prepared tissue sections were stained with H\&E. Selected sections were stained with Von Kosei's stain (Mallory; 1942) for demonstration calcium depositions, Mallory's phosphotungstic acid haematoxylin (Mallory; 1942) for collagen fibers depositions and Periodic acid Schiff (PAS) stain according to (MacManus, 1948) for glycogen depositions in myocardial fibers. 
Estimation of Selenium level

Serum, liver, and kidneys tissues samples were digested according to the method described by Koh \& Benson (1983) and analyzed by the method described by Shimadzu (Atomic absorption spectrophotometer cook book- Shimadzu Corporation). The instrument used was Atomic Absorption spectrophotometer manufactured by Shimadzu (Model AA6800) connected to Hydride Vapor Generator (Modal HVG-1).

\section{Results}

\section{Clinical observation}

Seven calves died without premonitory signs. The other five calves died 12-18 hours after the onset of reduced appetite and dullness. Stiffness, tremors and shallow respiration were prominent in diseased cases. Sever diarrhea and dehydration was reported in two calves. Eight calves died from a single flock consisted of 80 calves.

\section{Clinical pathology}

The laboratory has the opportunity to assay clinical hematology and chemistry data for eight affected cases prior to death. The obtained data compared with the normal physiological parameters used to obtain in a apparently healthy group of the same ages was listed in Table (1).

The obtained data showed remarkable signs of anemia in all studied cases represented by reduction of hemoglobin concentration and slight decline in PCV\% and total erythrocytes comparing to the normal levels used to be recorded in apparently healthy cases of the same age. The erythrocytes picture showed signs of iron deficiency anemia. The obtained data showed increase in Glucose (Glu), Creatine phosphokinase (CPK), lactate dehydrogenase (LDH), Aspartate aminotransferase (AST) and Lactic acid (LA) in all cases. This is coincided with

Table 1. The Hematology and Chemistry data of Camels

\begin{tabular}{lcc}
\hline \multirow{2}{*}{ Parameter } & \multicolumn{2}{c}{ Recorded Ranges } \\
\cline { 2 - 3 } PCV \% & In diseased cases & in apparently healthy cases \\
\hline $\mathrm{HB} \mathrm{G} / \mathrm{dl}$ & $17-23$ & $21-33$ \\
$\mathrm{RBCs} 10^{12} \mathrm{~L}$ & $8.2-10.4$ & $10-16$ \\
Glucose mg/dl & $5.0-7.4$ & $6.2-10.2$ \\
$\mathrm{CK} \mathrm{U} / \mathrm{L}$ & $50-250$ & $71-141$ \\
$\mathrm{LDH} \mathrm{U} / \mathrm{L}$ & $1720-3200$ & $16-300$ \\
$\mathrm{AST} \mathrm{U} / \mathrm{L}$ & $1895-1965$ & $180-600$ \\
$\mathrm{ALT} \mathrm{U} / \mathrm{L}$ & $995-1065$ & $45-155$ \\
$\mathrm{Ca} \mathrm{mg/dl}$ & $10-50$ & $2-54$ \\
$\mathrm{Pi} \mathrm{mg/dl}$ & $9-12$ & $8.3-12.7$ \\
$\mathrm{Mg} \mathrm{mg} / \mathrm{dl}$ & $9.1-12.5$ & $3.1-8.5$ \\
$\mathrm{L.A.} \mathrm{mmol/L}$ & $2.5-2.9$ & $2.2-4.2$ \\
$\mathrm{Cu} \mathrm{ug} / \mathrm{dl}$ & $6.4-12.8$ & $2.3-4.5$ \\
$\mathrm{Iron} \mathrm{ug/dl}$ & $38-62$ & $62.2-92.2$ \\
\hline
\end{tabular}


Emir. J. Agric. Sci. 2001. (13) : 11-17

http://www.cfs.uaeu.ac.ae/research/ejas.html

low levels of copper and iron comparing to the normal levels used to be recorded in apparently healthy cases ( Table 1). The other parameter lies in the normal physiological ranges to apparently healthy cases.

\section{Selenium level}

The average selenium level was detected in 8 serum samples prior to death and in liver and kidney of 12 dead cases ( Table 2 ). The average selenium level was less than $35 \mathrm{ppb}$ in serum of diseased camel calves and less than $0.20 \mathrm{ppb}, 0.65 \mathrm{ppb}$ in liver and kidney tissues respectively.

\section{Necropsy findings}

Hydrothorax and hydro-pericardium were observed. The pericardial sac filled with straw yellow like fluid contained whitish fibrinous flacks. Various degrees of necrosis were the common findings among all examined cases. Very large irregular whitish necrotic areas were distributed over the epicardial wall of left ventricle (Fig.1). This necrosis was represented with linear whitish areas on the left atrial and right ventricle walls. The cut section revealed different degrees of necrosis in myocardial layers (Fig. 2).

Lung congestion and edema were seen in all affected calves except three cases that showed hepatization of apical and cardiac lobes of both lungs. The venous congestion was the common pathological lesions of the other internal organs. The cardiac apex of severely affected cases (4 out of 12 cases) was completely whitish yellow in color (Fig 1). In addition, a sandwich-like (Zone necrosis) was found between epicardial and endocardial layers in the cardiac wall of the four heart compartments as well as the internal septum. Small focal whitish necrotic areas were seen also on the endocardium wall of the left ventricle of these four cases.

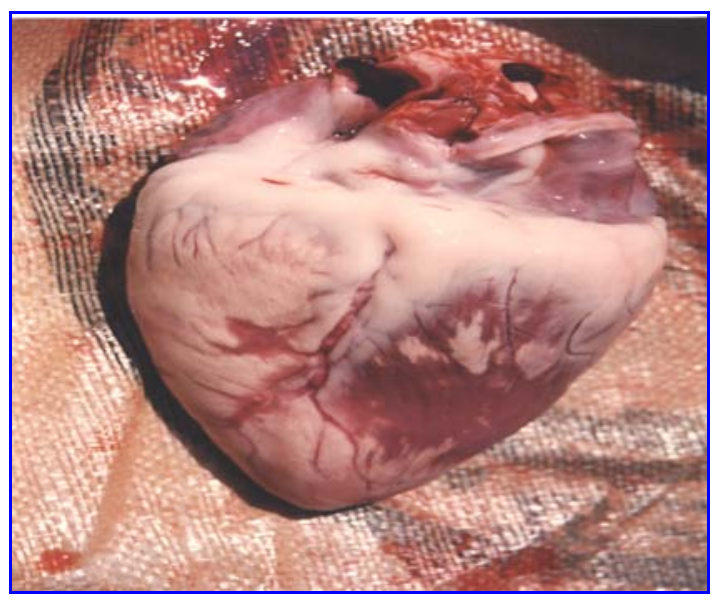

Figure 1. Very large irregular whitish necrotic areas that distributed allover the epicardial wall of left ventricum, Heart of camel calf

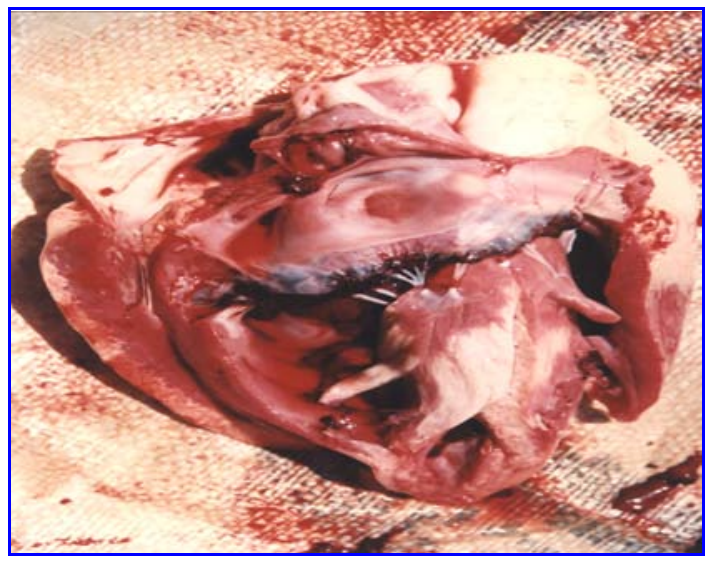

Fig. 2. Cut section in Heart of camel-calf showed different degrees of necrosis in myocardial layers.

\section{Histopathology Finding}

Cardiac tissues of all dead cases showed different pathological alterations. Focal areas of non-inflammatory coagulative necrosis distributed all over the left ventricle (Fig 3). These necrotic areas showed swollen myocardial fibers with granular cytoplasm and loss of striation. This was accompanied by severe blood vessels congestion, edema, anitschkow cells activation and lymphocytic infiltration. Quite a few unaffected myocardial fibers were seen in between the narcotized fibers. Various degrees of calcium salt deposition were seen all over the necrotic areas (Fig 4). This represented by purplish color granules of different sizes stained black in color when vonkossa's staining method was applied (Fig 5). The calcium salts were completely replaced the myocardial fibers in few focal areas. 


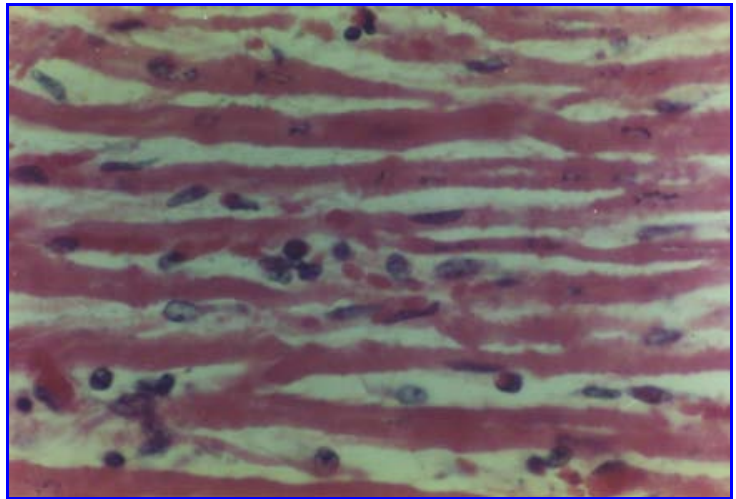

Figure 3. Focal area of non-inflammatory coagulative necrosis that distributed allover the left ventricular walls . (Heart tissues, calf -camel, H\&E, X 300)

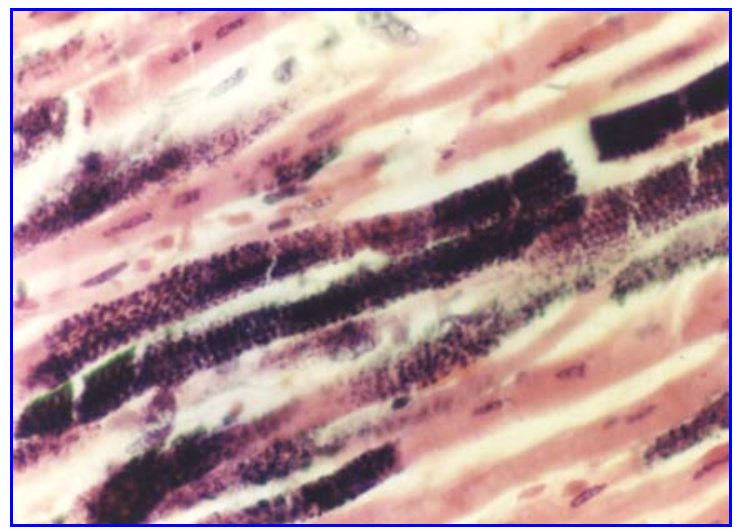

Figure 4. Deposition of calcium salts in necrotic myocardial fibers.

(Heart tissues, calf camel, H \& E, X 300)

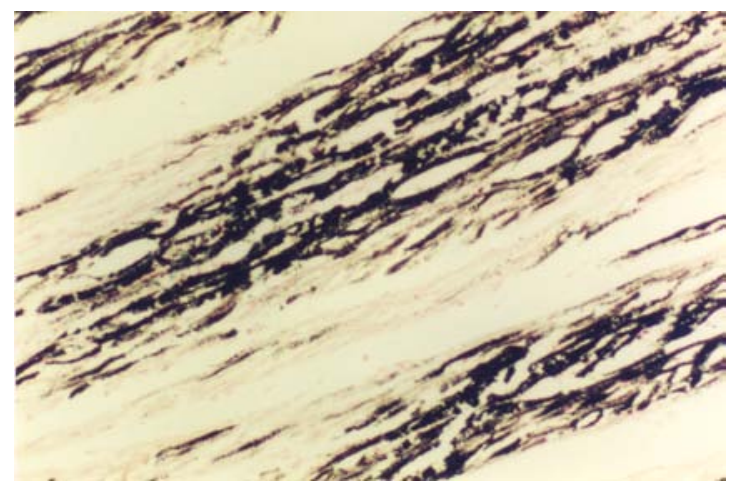

Figure 5. Calcium salt deposition (Black color) as seen in the necrotic myocardial fibers by Vonkossa's stain ( Heart of calf-camel, X60)

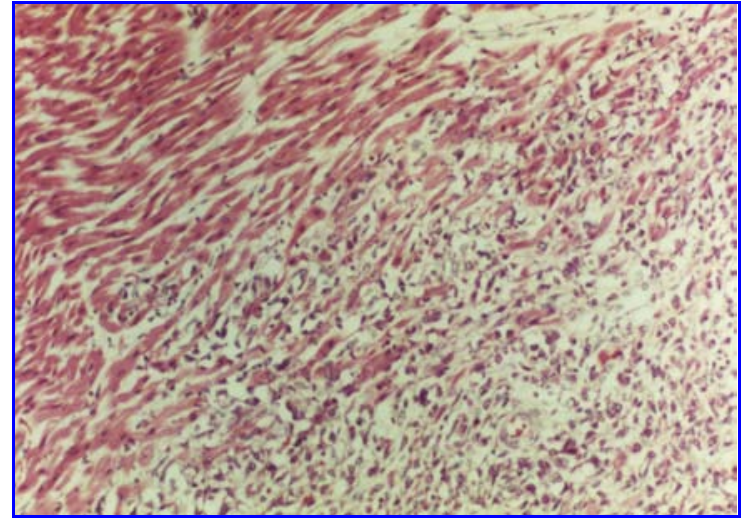

Figure 6 Fibrous areas that seen allover the myocardial tissues, camel calf heart tissues (H\&E, X60)

Wide fibrous areas were seen mainly in the myocardium (Fig 6). The myocardial fibers were completely replaced by proliferated fibrous tissues. These areas were surrounded with coagulative necrotic areas. Calcium salt deposition was seen also in these fibrous areas (Fig. 7). Foreign body macrophages were seen around the calcified areas in two cases.

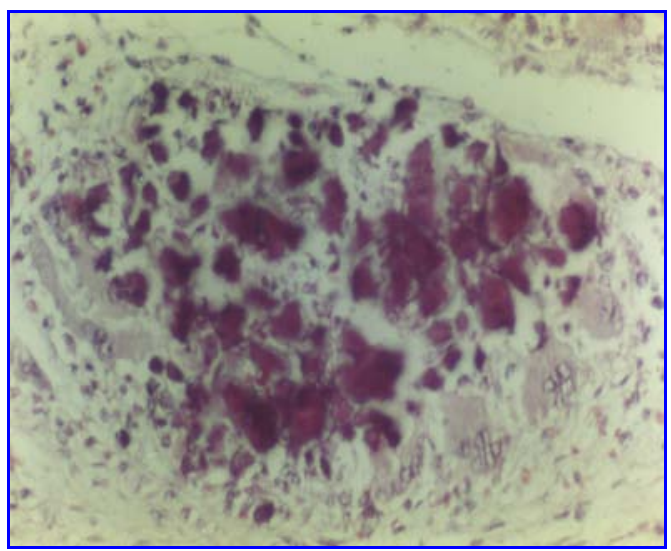

Figure 7. Foreign body macrophages that seen around the calcified areas, Camel calf heart tissues (H\&E, X600).

The predominant inflammatory reaction was the presence of histocytes and fibroblasts in addition to lymphocytic and nautrophilic granulocytes infiltration with a lesser degree. Most of these pathological alterations were seen at the outer and middle zone of the myocardial layers, while few of these pathological alteration were close to the endocardium . 
Emir. J. Agric. Sci. 2001. (13) : 11-17

http://www.cfs.uaeu.ac.ae/research/ejas.html

Table 2. Average selenium levels in the studied cases

\begin{tabular}{ccc}
\hline & $\begin{array}{c}\text { Average level in diseased } \\
\text { cases }\end{array}$ & $\begin{array}{c}\text { Average level in healthy } \\
\text { cases }\end{array}$ \\
\hline Serum & $<35 \mathrm{ppb}$ & $100.1-138.8(8)$ \\
Liver tissue & $<0.20 \mathrm{ppb}$ & Unknown \\
Kidney tissue & $<0.65 \mathrm{ppb}$ & Unknown \\
\hline
\end{tabular}

\section{Discussion}

Muscular dystrophy due to trace element disorders have been implicated in a wide variety of myopathies in different farm animals (Hutchinson et al., 1982). Scanty information is available concerning this syndrome in calves-camel (Zhang et al.,1986). The described clinical signs in the current study agreed with that reported for selenium deficiency in other farm animals (Fowler, 1986; Fowler, 1993 Hutchinson et al., 1982 and Oldfield,1983). Muscular stiffness, ataxia, weakness, paralysis, diarrhea, or sudden death due to cardiac muscle necrosis were considered among the most predominant clinical signs. The recorded high incidence of deaths in a single flock $10 \%$ due to selenium deficiency could be attributed to selenium deficiency in the dam's milk. This controversially with the fact that camel's milk is considered a potential source of selenium (Al- Awadi \& Srikumar, 2001). This in turn raise a question about the possibility of inadequate dietary supplementation of the dams or due to incorporation of certain elements that antagonize selenium assimilation such as copper in the dam's foodstuff. Similar conditions were described in USA (Van Vleet, 1980).

The obtained clinical data showed signs of erythrocyte anemia represented by decrease levels of PCV, erythrocyte count, hemoglobin, copper, and iron. The clinical symptoms of myopathy were manifested by increase activity of plasma enzymes of cardiac and muscular origin, such as AST, ALT, CPK and $\mathrm{LDH}$ as well as glucose. This is agreed with what had been recorded in other animals (Blood and Radostits, 1980).
These clinical parameters could be of valuable diagnostic aids, study the extent of muscular damage and follow up the diseased condition. The obtained results showed that affected cases yielded a very low Se level in the serum of diseased cases (35 ppb), compared with the normal values (100.1 $138.8 \mathrm{ppb}$ ) described for healthy calves (Hamliri et al.,1990).

According to the authors' knowledge, no data is available concerning Se level in liver and renal tissues of camels. In the current study the detected Se levels was $<0.02$ in liver tissues and $<0.65 \mathrm{ppb}$ in renal tissues. This is similar to that observed in other species in selenium deficient cases (Blood et al., 1990). Our gross and histopathological findings were similar to those described by others in cases of myodegeneration related to selenium deficiency (Decker and McDermid, 1977; Jones and Hunt, 1983 and Jupp et.al.1985) .

Association of low blood selenium levels and generalized skeletal and cardiac muscle degeneration was described in poor performing racing horses ( Blackmore et al.,1979 ), foals ( McClung,1974 ), calfcattle ( Segall et. al.,1977 ), lambs ( Mass et. al. , 1984 ) , Ilama (Fowler , 1986; Fowler , 1993 and Oldfield , 1983) and Zoo camels (Decker and McDermid, 1977).

\section{References}

AL - Awadi, F.M. \& T. S. Srikumar, 2001. Trace elements and their distribution in protein fractions of camel milk in comparison to other commonly consumed milk. J Dairy Res. 68 (3): 463-9. 
Blackmore, D .J., K. Willett and D. Agness. 1979. Selenium and gammaglutamyl transferase activity in the serum of thorough-breds . Res Vet Sci 26:76-80,1979.

Blood C.D. and M. O. Radostits, 1980. Diseases caused by nutritional deficiencies, Chapter 29,Veterinary Medicine. Seventh E.d. Bailliere and Tindall press, ISBN 0-7020-1286-6 :1187-1198

Decker, R .A. and A. McDermid, 1977. Nutritional myopathy in young camel. J ZOO Anim. Med. 8: 20-21.

Finlayson, R., L. F. Keymer and V. J. A. Monton. 1971. Calcific cardiomyopathy in young camel. J.Camp.Path.81:71-78.

Fowler, M.E., 1986. Selenium-friend or Foe. ILamas 31:37-43.

Fowler, M.E. 1993. Medicine and surgery of south American camelids, Ilamas, alpaca, vicuna, guanac, Iowa State University Press Ames, Thrid printing 1993. PP. 18-19.

Hamliri, A.,1989. Selenium deficiency of sheep in Morocco. assessment ,occurrence and prevention $(\mathrm{PhD}$ thesis, University of Minnesota, Minneapolis, USA.

Hamliri A., K. Khallaayoune, W. D. Johnson and M. Kessabi. 1990. The relationship between the concentration of selenium in the blood and the activity of glutathione peroxidase in the erythrocytes of the Dromedary Camel (Camellus Dromedarius). Short Communication. Vet.Res.Comm, $14: 27$ - 30 .

Horton, G.M.J.1977. Parenteral and oral administration of vitamin $\mathrm{E}$ and selnium to pregnant ewes. In European
Association for animal production, $28^{\text {th }}$ meeting in Brussels, pp 3-14.

Hutchinson, L .J., R. W. Scholz and T. R. Drake. $1982 . \quad$ Nutritional myodegeneration in a group of Chianina heifers. JAVMA, Vol. 181, No. 6, 581- 584.

Jones T.C. and R. D. Hunt, 1983. Veterinary Pathology, Fifthedition, Leaf Febigen. Philadelphia (PP 1045, 1064 and 1149-1152).

Jupp, K. V. F.; P. C. Kennedy and N. Palmer, 1985. Pathology of Domestic Animals, Third Edition Vol.3, Academic Press, INC (London) LTD. (PP 29-30).

Koh, T. S. and Benson, T. H.1983. Critical re-appraisal of fluorometric method for determination of Selenium in Biological materials. J Assoc. off Anal. Chem. (Vol. 66,No 4,pp 918- 926).

McManus, J. F .A.1948. Stain Technology, 23:99,1948(A.F.I.P Modification) .

Mallory, F. B. 1942. Pathological Technique; philodelphia, WB saunders Co., pp. 76 , pp. $144 \&$ pp. 156 (A.F.I.P. modification ).

Mass, J.; M. S. Bulgin; B. C. Anderson and T. M. Frye, 1984. Nutritional myodegeneration associated with vitamin $E$ deficiency and normal selenium status in lambs . JAVMA, vol. 184 No. 2 PP: 201-204.

McClung, J. 1974. New selenium supplementation rules in effect: AFMA will seek broader use. Feedstuffs 46(6):2; 49.

Oldfield, J.E. 1983.Two faces of selenium. llama world 1(4):10-11. 
Emir. J. Agric. Sci. 2001. (13) : 11-17

http://www.cfs.uaeu.ac.ae/research/ejas.html

Segall, H. J., D. M. Siegal and B. B Norman, 1977.A rapid screening blood spot test for seleniumresponsive disease in cattle. Calif. Vet 31: 10-11.

Van Vleet, J. F., 1980. Current knowledge of selenium - vitamin E deficiency in domestic animals . J Am Vet Med. Assoc. 176 (4) : 321- 325.
Wisner, H. and B. Schlotke. 1975. White muscle disease at the Hellabrunn zoo in Munich. 17 Vet. Erkr. Zoo. wild. Tunis Berlin. PP. 217-220.

Zhang, C . L., SU. J.L. and Y.Q. Feng 1986. A survey of sway disease (selenium deficiency of camels). Chinese J Vet. Med. 12:17:18. 